\title{
Radioactive Waste Disposal
}

\author{
By CLINTON C. POWELL, M.D., and HOWARD L. ANDREWS, Ph.D.
}

$\mathrm{W}$ ITH the increased use of reactor-produced isotopes in research, many organizations are today faced with the problem of the disposal of radioactive waste materials. Many of the materials are either too active to put into municipal sewer lines or are in forms not suitable for liquid disposal. Large isotope-production centers, such as Oak Ridge and Hanford, have special facilities for handling waste products, but the average urban laboratory is not so equipped. Space for storage until decay has proceeded to safe levels may be at a premium, and land burial is often difficult and of uncertain permanence.

Although land burial may be satisfactory in special cases, it is generally undesirable for several reasons. Obviously, extreme care must be taken to avoid seepage and the subsequent contamination of surface or ground water. The selection of a suitable burial site presents problems: An area which today appears unattractive for construction and habitation may very soon become desirable for a building program. After weighing these considerations and being forced

Dr. Powell, now with the National Cancer Institute, National Institutes of $B$ ealth, Public Health Service, was formerly radiation safety officer for the National Institutes of Health, Bethesda, Md. Dr. Andrews is chief of the section on nuclear radiation biology, National Institute of Arthritis and Metabolic Diseases, National Institutes of Health. All members of the radiation health protection group at the National Institutes of Health have contributed to the development of the system for disposal of radioactive waste materials described in this report. to remove one land burial depot, the National Institutes of Health decided upon burial at sea as the most satisfactory method of ultimate disposal for all radioactive wastes which cannot be safely admitted to the municipal sewage system.

\section{Concrete Burial Vaults}

The present system for disposal of radioactive wastes is the result of over $21 / 2$ years of experimentation with various containers and methods of sealing. Two types of containers determined unsuitable were steel drums and garbage cans. These roll if placed on their sides, are inconvenient to handle, and will disintegrate rapidly in sea water.

Standard, commercially available, concrete burial vaults were found to be satisfactory basic containers. Child-size vaults, 193/4 by 183/4 by 44 inches (outside dimensions), hold about 5.3 cubic feet of material and cost about $\$ 25$ each. The cost is negligible compared to the total cost of the average experiment using radioactive isotopes. Vaults are also available in larger sizes, up to 36 by 28 by 93 inches, for the disposal of large items of equipment not readily broken down, but the small size is more generally useful and more easily handled.

The burial vaults may be lifted by steel cables attached to the four lifting eyes cast in the bottom. Pending disposal, they occupy a minimum of space and may be stacked if allowable floor loading permits.

As waste products are brought in from the various laboratories, monitors pack them in the vault as compactly as possible. Containers of liquid wastes may be put in, usually without concentration of the materials. An alternate 
method involves mixing the liquid wastes with a prepared sand-cement mix; this is allowed to harden and then placed near the center of the vault. Dilute solutions may be concentrated by chemical reactions, evaporation, or ion exchange columns before disposal. Contaminated furniture, such as hoods, is taken apart for more compact stowage. Relatively active materials are placed near the center of the vault to reduce the radiation level at the outside by both distance and shielding. At the present time no attempt is made to concentrate routinely either solid or liquid wastes, but this will be done in the future as suitable methods are developed.

The vaults are filled with waste materials to within 3 to 4 inches of the top, then filled flush with a concrete mix. The mix is made with somewhat more than the usual amount of water to facilitate a complete filling of all voids which would add to the buoyancy and increase the chance of crushing by external water pressure. The final pouring is made with the vault suspended by the steel cables so that subsequent lifting will not crack the concrete cap. The finished product, ready for disposal, weighs from 900 to 1,300 pounds and is readily handled with a small chain hoist. The sealed container is weighed carefully to insure that it has a substantial negative buoyancy.

Concrete burial vaults sealed as described should also be satisfactory where land burial rather than sea disposal is practiced. Contact between the active contents and surrounding earth and water will be minimized, and removal will be facilitated if a new burial site has to be used.

\section{Disposal at Sea}

When a load of from 10 to 20 tons has accumulated, the vaults are trucked to the United States Coast Guard moorings at Berkeley (Norfolk), Va. To date none of the shipments has presented any radiation hazard to the truck drivers or handlers, but all shipments are routinely accompanied by a monitor in case of accident. The vaults are loaded from the pier to the deck of a Coast Guard cutter, using the ship's cargo winch for hoisting. The load is put overside in not less than 1,000 fathoms of water, which in the Norfolk area means from 75 to 100 miles off shore. Bearings of each disposal point are taken by the navigator of the cutter, reported to the monitor accompanying the shipment, and later recorded.

Each discarded vault represents almost a monolith that will probably not disintegrate appreciably in 100 years. Since the seal between the cement cap and the body of the vault is probably not watertight, and no attempt is made to make it so, there will undoubtedly be a slow diffusion of material through this joint. Contamination by diffusion should be very small, however, and dilution by surrounding sea water very great. Radioactive decay during the period the structure is intact will reduce the activity of most commonly used isotopes to undetectable levels. Even 5.3-year $\mathrm{Co}^{60}$ will decay to nearly $1 / 1,000,000$ of its original activity in 100 years. If the block eventually crumbles and exposes the contents, any undecayed products will be greatly diluted with large volumes of sea water.

\section{Conclusions}

It seems unlikely that this method of disposal, even if practiced by the majority of isotope users except the Atomic Energy Commission production plants, will have any detectable effect on commercial or sport fishing. The radioactivity associated with the potassium normally present in sea water amounts to about 1,000 curies per cubic mile, and the natural radium content of sea water will average perhaps 4 curies per cubic mile. It is most unlikely that these levels would be appreciably augmented by even a large-scale disposal program.

Disposition at depth appears to answer most of the objections to land burial and is much to be preferred to indiscriminate dumping into sewerage systems. A still greater factor of safety might be obtained by disposal in one of the stagnant areas where circulation with the bulk of the ocean water is relatively low, but these areas are less accessible than the one presently in use. 